\title{
Substance P Abolishes the Facilitatory Effect of ATP on Spontaneous Glycine Release in Neurons of the Trigeminal Nucleus Pars Caudalis
}

\author{
Zhi-Ming Wang, Shutaro Katsurabayashi, Jeong-Seop Rhee, Malcolm Brodwick, and Norio Akaike \\ Cellular and System Physiology, Graduate School of Medical Sciences, Kyushu University, Fukuoka, 812-8582, Japan
}

Glycine release was facilitated by the activation of presynaptic ATP receptors $\left(\mathrm{P}_{2 \mathrm{x}}\right.$-type) in a preparation of dissociated trigeminal nucleus pars caudalis neurons in which the native synaptic boutons were preserved. The action of ATP was completely blocked by substance $\mathrm{P}$ (SP) without alteration of the miniature IPSC (mIPSC) amplitude distribution. SP itself had no effect on mIPSC frequency or amplitude. The inhibitory effect of SP on ATP action was blocked by CP99994, indicating that the SP receptors are of the neurokinin-1 type. The ATP-induced facilitation of the mIPSC frequency was unaffected by $\mathrm{Cd}^{2+}$. Moreover, SP did not inhibit the increase in mIPSC frequency induced high $\mathrm{K}^{+}$application, suggesting that SP did not modulate voltage-dependent calcium channels or subsequent steps in the release process.

KT5720 and phorbol 12-myristate 13-acetate did not block SP action, indicating that neither the cAMP-protein kinase A nor the protein kinase $C$ pathway mediates the SP effects. However, in the presence of $\mathrm{N}$-(6-aminohexyl)-5-chloro-1- naphthalene sulphonamide (W-7), SP was no longer able to inhibit the ATP-induced stimulation of mIPSC frequency. 1-[N,O-bis(5-isoquinolinesulfonyl)- $N$-methyl-L-tyrosyl]-4-phenylpiperazine also suppressed the SP action, suggesting that SP modulates $\mathrm{P}_{2 x}$ receptors via a $\mathrm{Ca}^{2+}$ /calmodulin-dependent protein kinase II-mediated pathway. In conventional whole-cell mode, the presence of $\mathrm{W}-7$ in the patch pipette did not affect the SP inhibitory action. Thus, SP is not likely to be generating its modulation through the production of a retrograde signal (involving calmodulin) from the postsynaptic cell to the presynaptic boutons.

These results are the first demonstration of the modulation of one presynaptic receptor by another. Because SP inhibits the ATP stimulation of glycine release, SP may play a significant role in hyperalgesia or chronic pain.

Key words: dissociated neurons; substantia gelatinosa neuron; glycinergic nerve terminal; ATP and substance $P$ receptors; calmodulin; CAM kinase II; glycinergic mIPSC; modulation; pain
Despite an intense effort to understand the neural circuitry underlying nociception in the spinal cord, there are still many uncertainties regarding the function of substance P (SP). Seemingly contradictory data from behavioral and electrophysiological experiments have been found regarding the role of SP. For example, neurokinin-1 (NK-1) receptor antagonists reduce the response to maintained inflammatory pain models but have no effect on brief noxious stimulation (Seguin et al., 1995). Electrophysiological experiments also indicate that NK-1 receptor inhibition decreases long-term noxious stimulation without a parallel effect on short-term C-fiber responses (Chapman and Dickenson, 1993). The destruction of dorsal horn neurons containing NK-1 receptors "left responses to mild noxious stimuli unchanged, but markedly attenuated responses to highly noxious stimuli and mechanical and thermal hyperalgesia" (Mantyh et al., 1997). Clearly the nature of the response, as well as the duration and magnitude of the stimuli must be considered. Moreover, parallel

Received July 3, 2000; revised Feb. 6, 2001; accepted Feb. 14, 2001.

This work was supported by The Japan Health Science Foundation (No. 21279 and Research on Brain Science) and Kyushu University Interdisciplinary Programs in Education and Projects in Research Development (N.A.). We thank Drs. William Willis, Nada Lawand, and Megumu Yoshimura for advice and comments on this manuscript.

Correspondence should be addressed to Dr. N. Akaike at the above address. E-mail: akaike@mailserver.med.kyushu-u.ac.jp.

Dr. Brodwick's present address: Department of Physiology and Biophysics, University of Texas Medical Branch, Galveston, TX 77555-0641.

Copyright $\odot 2001$ Society for Neuroscience $0270-6474 / 01 / 212983-09 \$ 15.00 / 0$ pathways mediating pain sensation or reflex activity complicate analysis.

SP mediates a bewildering variety of cellular responses. For example, certain subtypes of voltage-dependent calcium channels are inhibited by SP in rat nucleus basalis neurons. This inhibition appeared to be mediated by a pertussis toxinindependent G-protein (Margeta-Mitrovic et al., 1997). A variety of G-proteins are coupled to SP receptors (Nishimura et al., 1998). For submandibular neurons the decrease in calcium channel activity was reduced by protein kinase $\mathrm{C}$ (PKC) but not by protein kinase A (PKA) (Yamada et al., 1999). In contrast, locusttachykinins produced a depolarization mediated by cAMP and PKA (Lundquist and Nassel, 1997). In astrocytoma cells, SP and histamine appear to transiently raise the intracellular calcium levels through a mechanism involving phosphoinositide metabolism, which is then followed by a decrease mediated by a PKC stimulation of calcium pumps (Young et al., 1998). Moreover, inositol triphosphate levels increased within $30 \mathrm{sec}$ of SP application to guinea pig urinary bladder (Martin et al., 1997). In adenoid tissue explants, the ciliostimulatory effect of SP appears to be mediated by nitric oxide (Runer and Lindberg, 1999). Last, SP activates mitogen-activated protein kinase with the expression of immediate-early genes in human astrocytoma cells (Luo et al., 1997).

Because of the complexity of the neural circuitry and the added complexity of the temporal relationships of the various inputs, it is difficult to resolve the cellular mechanisms underlying the response to sensory inputs. A preparation of acutely isolated 
neurons from the substantia gelatinosa (SG) of the trigeminal nucleus pars caudalis retaining functional synaptic boutons (Rhee et al., 2000) provides a simplified system for studying the effects of modulators on synaptic transmission. The various nerve endings can be functionally isolated with appropriate inhibitors.

Here we demonstrate a role for SP in the modulation of the ATP-induced stimulation of glycine release. This effect of SP appears to be activated by the calmodulin-CaM kinase II system located in the presynaptic terminal. This finding represents the first demonstration to our knowledge of the presynaptic modulation of one receptor type by another.

\section{MATERIALS AND METHODS}

Preparation. Ten- to 14-d-old Wistar rats were decapitated under pentobarbital anesthesia. The spinal cord was quickly removed and was sliced at a thickness of $400 \mu \mathrm{m}$ with a microslicer (DTK-1000; Dosaka, Kyoto, Japan). The spinal cord slices were kept in an incubation medium saturated with $95 \% \mathrm{O}_{2}$ and $5 \% \mathrm{CO}_{2}$ at room temperature $\left(22-25^{\circ} \mathrm{C}\right)$ for at least $1 \mathrm{hr}$. Thereafter, the slices were transferred into a $35 \mathrm{~mm}$ culture dish (Primaria 3801; Becton Dickinson, Franklin Lakes, NJ), and the dorsal horn of the spinal cord was identified under a binocular microscope (SMZ-1; Nikon, Tokyo, Japan). A fire-polished glass pipette was placed lightly onto the surface of the dorsal horn and was vibrated horizontally. We recorded the vibration movement with digital video camera and measured the speed and distance of movement. The speed and distance were regulated by an AC power supply. The vibration movement in our experiment was $\sim 3-5 \mathrm{~Hz}$ for $2 \mathrm{~min}$ and over a $0.3-0.5$ $\mathrm{mm}$ distance (Rhee et al., 1999). After the slices were removed, the mechanically dissociated SG neurons adhered to the bottom of the dish within $10 \mathrm{~min}$. These neurons, which were dissociated without using any enzymes, retained some recognizable morphological features, including proximal dendritic processes. In addition some pinched-off synaptic boutons of a few micrometers in diameter remained attached and were capable of spontaneous release of neurotransmitter.

Electrical measurements. Electrical measurements were performed in the nystatin-perforated patch recording mode at a holding potential of $-60 \mathrm{mV}$ under voltage-clamp conditions. Patch pipettes were made from borosilicate glass tubes $(1.5 \mathrm{~mm}$ outer diameter, $0.9 \mathrm{~mm}$ inner diameter; G-1.5; Narishige, Tokyo, Japan) in two stages on a vertical pipette puller (PB-7; Narishige). The neurons were visualized with phase-contrast equipment on an inverted microscope (Diaphot; Nikon). The current and voltage were measured with a patch-clamp amplifier (CEZ-2300; Nihon Kohden, Tokyo, Japan), monitored on both an oscilloscope (Tektronix 5111A; Sony, Tokyo, Japan) and a pen recorder (Recti-Horiz 8K; Nippondenki San-ei, Tokyo, Japan), and stored on videotapes after digitization with a pulse-coded modulation processor (PCM-501 ES; Sony). The membrane currents were filtered at $1 \mathrm{kHz}$ (E-3201A Dicade Filter; NF Electronic Instruments, Tokyo, Japan), and data were digitized at 4 $\mathrm{kHz}$. The resistance between the recording electrode filled with the internal solution and the reference electrode in the external solution was 5-7 $\mathrm{M} \Omega$. All experiments were performed at room temperature $\left(22-25^{\circ} \mathrm{C}\right)$.

Data analysis. Events were counted and analyzed using "Detectevent" (Ankri et al., 1994) and IgorPro software (Wavemetrics, Lake Oswego, OR). Analysis of miniature IPSCs (mIPSCs) was performed with cumulative probability plots. Cumulative amplitude histograms were compared using the Kolmogorov-Smirnov test for significant differences. Statistically significant differences were assumed for $p<0.05$. Numerical values are provided as mean \pm SEM. Differences in amplitude and frequency distribution were tested by a paired two-tailed $t$ test.

Solutions. The ionic composition of the incubation medium was (in mM): $124 \mathrm{NaCl}, 5 \mathrm{KCl}, 1.2 \mathrm{KH}_{2} \mathrm{PO}_{4}, 24 \mathrm{NaHCO}_{3}, 2.4 \mathrm{CaCl}_{2}, 1.3 \mathrm{MgSO}_{4}$, and 10 glucose. The $\mathrm{pH}$ of the incubation medium was adjusted to 7.4 with $95 \% \mathrm{O}_{2}$ and $5 \% \quad \mathrm{CO}_{2}$. The ionic composition of the external standard solution was (in mM): $150 \mathrm{NaCl}, 5 \mathrm{KCl}, 2 \mathrm{CaCl}_{2}, 1 \mathrm{MgCl}_{2}, 10$ glucose, and $10 \mathrm{HEPES}$. $\mathrm{Ca}^{2+}$-free external solution contained (in $\mathrm{mM}$ ): $150 \mathrm{NaCl}, 5 \mathrm{KCl}, 3 \mathrm{MgCl}_{2}, 10$ glucose, $10 \mathrm{HEPES}$, and 2 EGTA.

While recording mIPSCs, these external test solutions routinely contained $3 \times 10^{-7} \mathrm{M}$ tetrodotoxin (TTX) to block voltage-dependent $\mathrm{Na}^{+}$ channels, $3 \times 10^{-6}$ м 6-cyano-7-nitroquinoxaline-2, 3-dione (CNQX), and $10^{-5}$ M DL-2-amino-5-phosphovaleric acid (DL-AP-5) to block glutamatergic responses, and $3 \times 10^{-6} \mathrm{M}$ bicuculline to block the $\mathrm{GABA}_{\mathrm{A}}$ responses. The ionic composition of the internal (patch pipette) solution
A

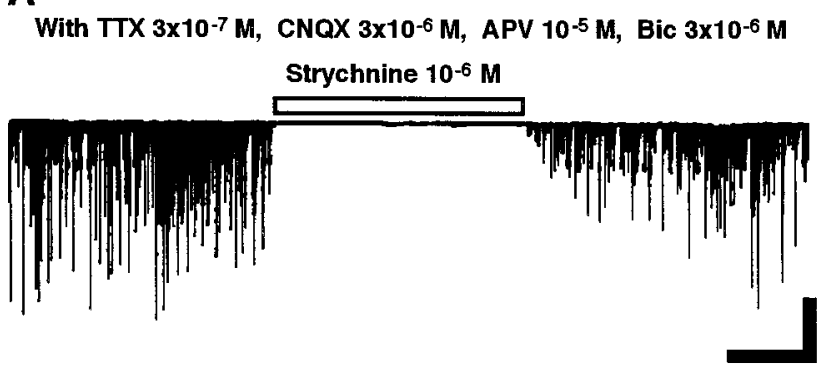

B

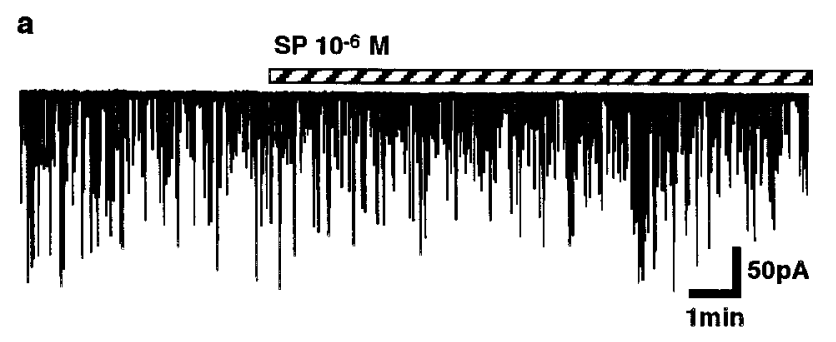

b
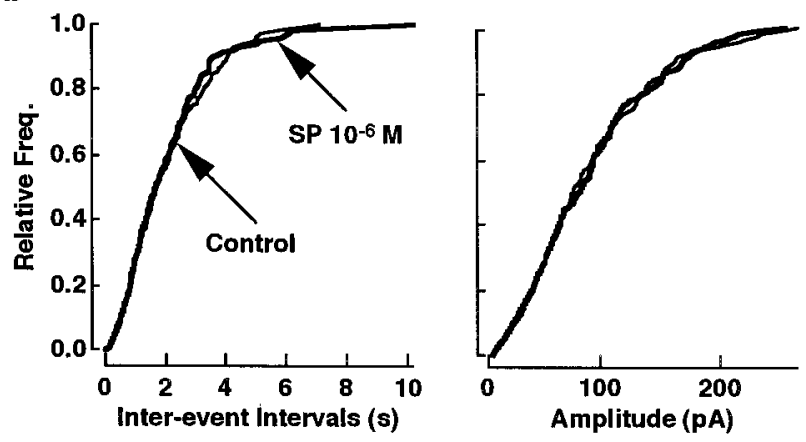

C

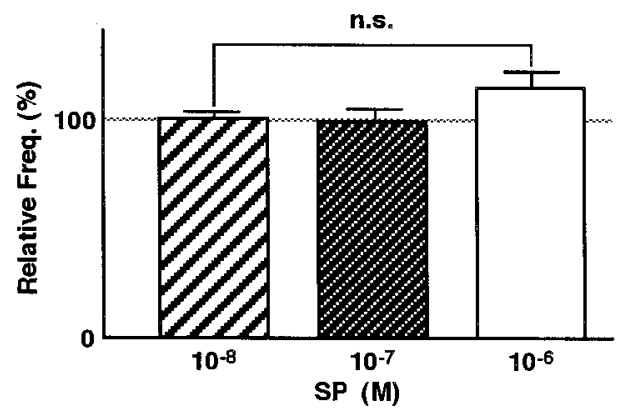

Figure 1. Effects of SP on glycinergic mIPSCs. A, The spontaneous inhibitory currents recorded from the "synaptic bouton preparation" were completely blocked in a reversible manner by $10^{-6} \mathrm{M}$ strychnine in the presence of $3 \times 10^{-7} \mathrm{M}$ TTX, $3 \times 10^{-6} \mathrm{M}$ CNQX, $10^{-5} \mathrm{M} \mathrm{AP-5}$, and $3 \times$ $10^{-6} \mathrm{M}$ bicuculline, indicating that the spontaneous mIPSCs are glycinergic. $B$, The SP at $10^{-6} \mathrm{M}$ itself facilitated the frequency of mIPSCs a little without altering the mI PSC amplitude distribution. $C$, The bar graph shows the frequency ratio of mIPSCs before and during application of SP. The vertical bar shows \pm SEM. SP at a low concentration $\left(10^{-8}-10^{-7} \mathrm{M}\right)$ had no effect on mIPSC frequency and the current amplitude distribution. Pooled data at $10^{-6} \mathrm{M}$ SP showed slightly increase of the mIPSC frequency but not significantly.

for the nystatin-perforated patch recording was (in mM): $20 \mathrm{~N}$-methyl-Dglucamine methanesulfonate, $20 \mathrm{Cs}$-methanesulfonate, $5 \mathrm{MgCl}_{2}, 100$ $\mathrm{CsCl}$, and $10 \mathrm{HEPES}$. The $\mathrm{pH}$ of the internal solution was adjusted to 7.2 with Tris-OH. Nystatin was dissolved in acidified methanol at $10 \mathrm{mg} / \mathrm{ml}$. The stock solution was added to the internal solution just before use at final concentration of $100-200 \mu \mathrm{g} / \mathrm{ml}$. 
A
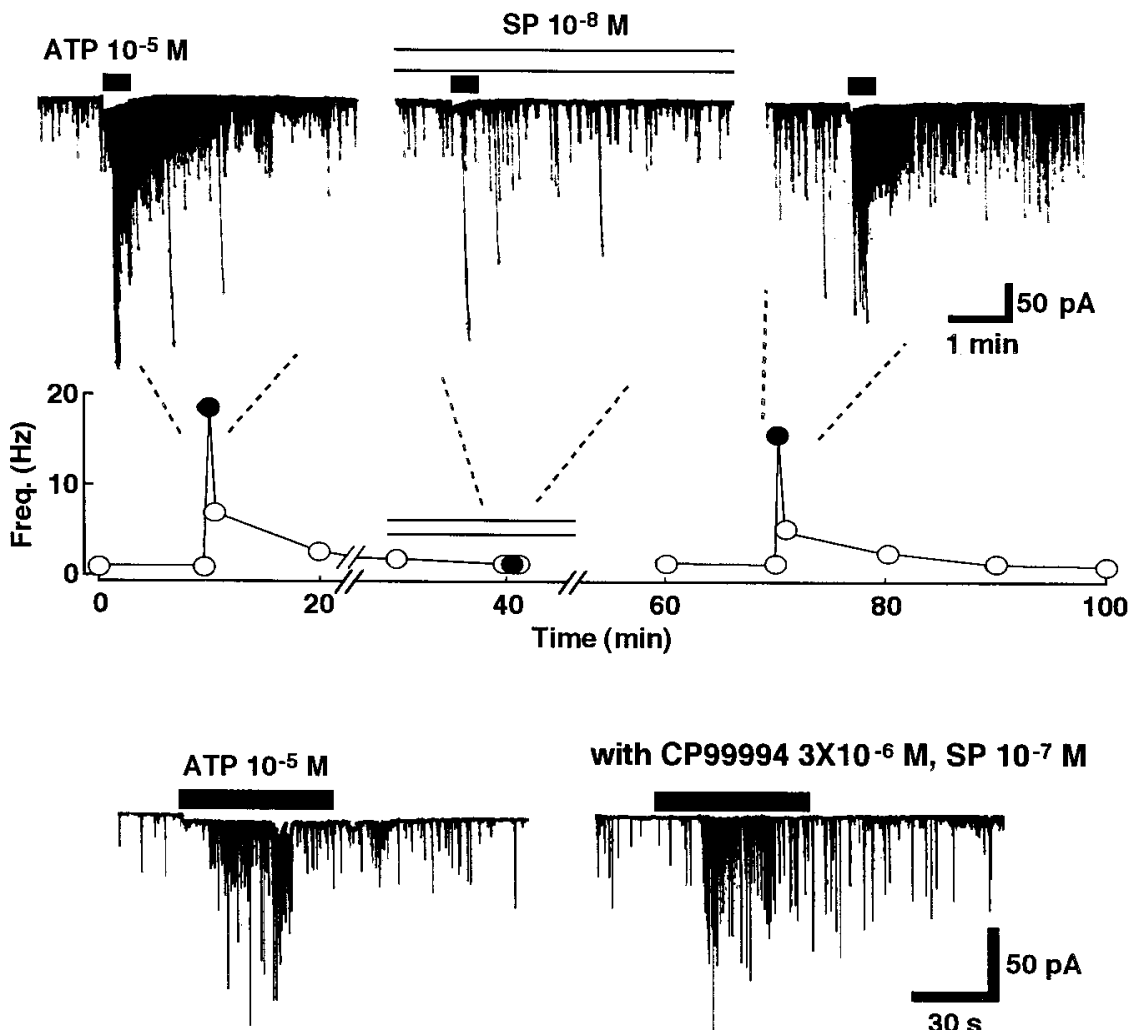

with CP99994 3×10-6 M, SP 10-7 M
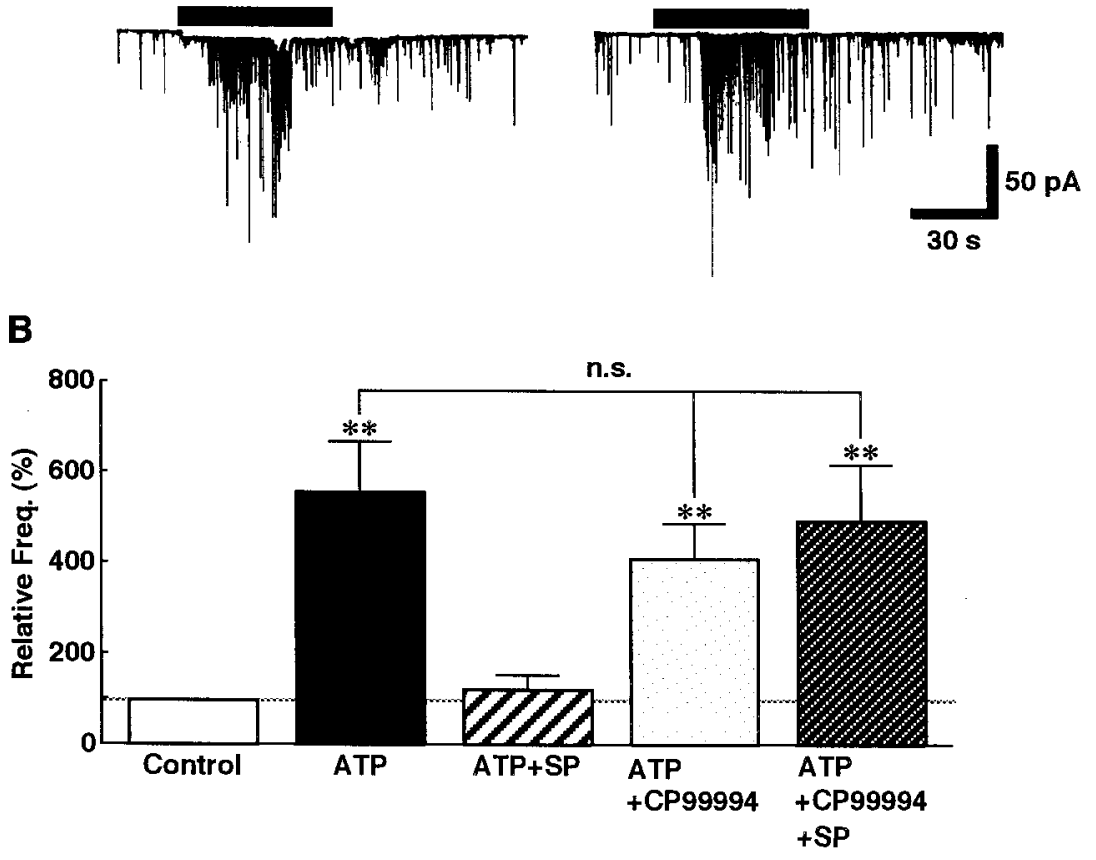

Drugs. Drugs used in the present study were $10^{-6} \mathrm{M}$ strychnine, $10^{-5}$ $\mathrm{M} \mathrm{AP-5,} 3 \times 10^{-6} \mathrm{M}$ bicuculline, $3 \times 10^{-6} \mathrm{M} \mathrm{CNQX}$, nystatin, and $10^{-6}-10^{-8}$ M substance P (SP) (Sigma, St. Louis, MO), $10^{-5}$ M ATP (Yamasa, Chiba, Japan), $3 \times 10^{-7}$ м TTX (Wako Pure Chemicals, Osaka, Japan), $10^{-6}$ м 1-[N,O-bis(5-isoquinolinesulfonyl)- $N$-methyl-Ltyrosyl]-4-phenylpiperazine (KN-62), $10^{-5}$ м PMA, $10^{-7}$ M $N-(6-$ aminohexyl)-5-chloro-1-naphthalene (W-7), and $10^{-6}$ M KT5720 (Calbiochem, La Jolla, CA). CNQX was dissolved in dimethylsulfoxide (DMSO) at $10^{-2} \mathrm{M}$ as a stock solution. A concentration of $3 \times 10^{-6} \mathrm{M}$ CP99994 was kindly provided by Dr. Yukio Takano (Fukuoka University, Fukuoka, Japan)

Drugs were applied by a "Y-tube system" (Akaike and Harata, 1994) that enables a solution exchange within $20 \mathrm{msec}$.

\section{RESULTS}

Spontaneous postsynaptic currents were recorded from the acutely dissociated SG neurons of the rat spinal trigeminal nucleus pars caudalis (layer II). Attached to these dissociated neurons were functional presynaptic nerve endings (Akaike et al.,
1992; Rhee et al., 1999). Electrical recordings were made using the nystatin perforated patch recording technique at a holding potential $\left(V_{\mathrm{H}}\right)$ of $-60 \mathrm{mV}$. All external test solutions contained $3 \times 10^{-7}$ м TTX, $3 \times 10^{-6}$ м CNQX, $10^{-5}$ M AP-5, and $3 \times$ $10^{-6} \mathrm{M}$ bicuculline. As shown in Figure $1 A$, after a control period of spontaneous mIPSCs, the mIPSCs were blocked by $10^{-6} \mathrm{M}$ strychnine in a reversible manner, indicating that the mIPSCs were glycinergic (Rhee et al., 2000).

SP itself did not alter the frequency or amplitude of glycinergic mIPSCs at the lower concentrations $\left(10^{-8}-10^{-7} \mathrm{M}\right)$. At a concentration of $10^{-6} \mathrm{M}$, SP slightly increased the mIPSCs frequency, although the increase was not significant (Fig. 1B,C). These data suggest that SP itself does not substantially modulate presynaptic glycine release or the postsynaptic glycine response.

ATP reversibly facilitated the frequency of mIPSCs without affecting the mean mIPSC amplitude in SG neurons. Indeed, the 
A

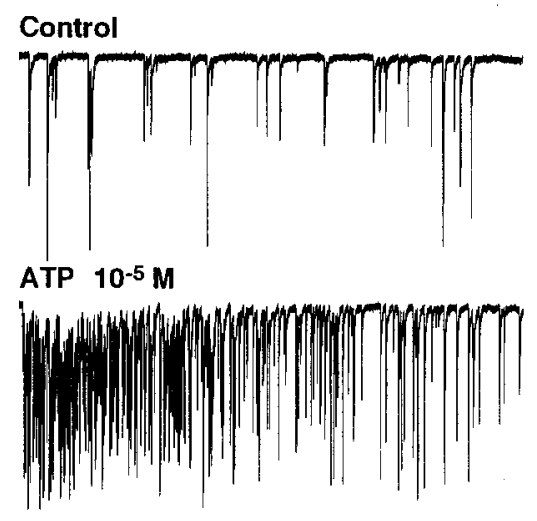

B

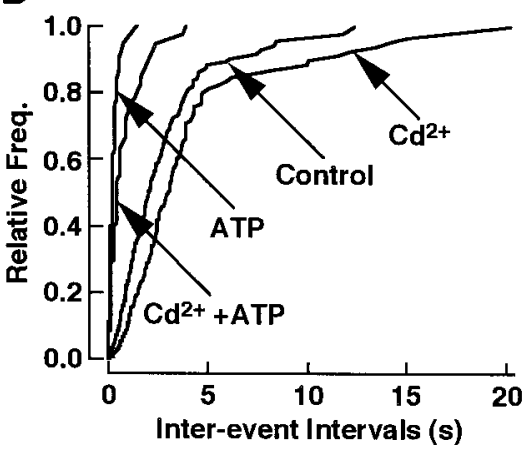

C

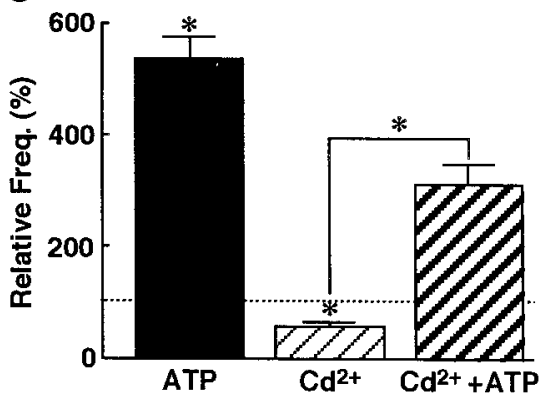

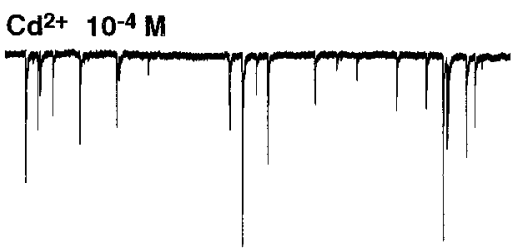
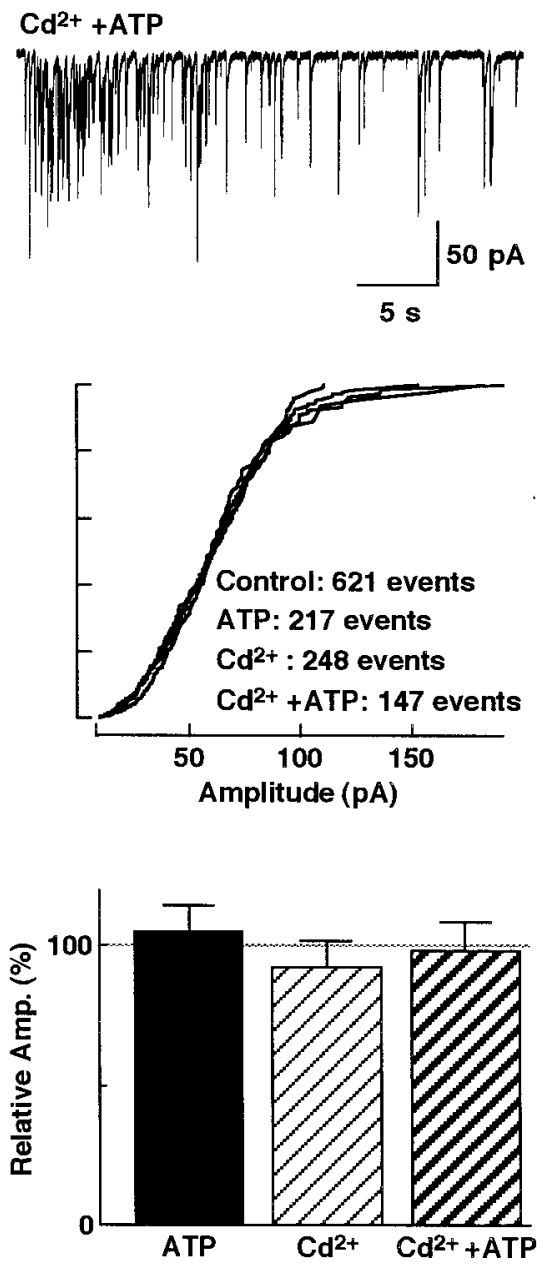

Figure 3. $\mathrm{Cd}^{2+}$ does not inhibit the ATP stimulation of the mIPSC frequency. $A$, Recordings of mIPSCs with and without $\mathrm{Cd}^{2+}\left(10^{-4}\right)$ in the top panels. The same experiment is shown in the presence of $10^{-5} \mathrm{M}$ ATP in the bottom panel. B, Normalized cumulative curves of interevent interval show that $\mathrm{Cd}^{2+}$ only slightly inhibited mIPSC frequency from control values or from the ATPstimulated state without altering the mIPSC amplitude. Numbers in the inset of the amplitude distribution indicate the numbers of samples used. $C$, Bar graph of the frequency ratio compared with control values of the ATP, $\mathrm{Cd}^{2+}$ alone, and $\mathrm{Cd}^{2+}$ in the presence of ATP. The vertical bars indicate \pm SEM. The asterisks indicate significant differences $\left({ }^{*} p<0.05\right)$ between the ATP and control state, between the $\mathrm{Cd}^{2+}$ and the control state, and between the $\mathrm{Cd}^{2+}$ and the $\mathrm{Cd}^{2+}+$ ATP. No significant differences $(p>0.05)$ were found for mIPSC amplitude.

facilitation was dependent on extracellular $\mathrm{Ca}^{2+}$, indicating that the ATP action was mediated by $\mathrm{P}_{2 \mathrm{X}}$ receptors or by the activation of voltage-dependent calcium channels on the glycinergic presynaptic nerve terminals. This facilitation occurred in the presence of $2 \mathrm{~mm}$ EGTA in the patch pipette, suggesting that the ATP effect is, perhaps, not generated in the postsynaptic membrane which then, in turn, generates a retrograde signal modifying mIPSC frequency. Note this claim is weakened by the low buffer capacity provided by the 2 mM EGTA; a large local influx of $\mathrm{Ca}^{2+}$ could initially overwhelm the local buffer near the inside surface of the membrane (Rhee et al., 2000). The facilitatory effect of ATP on mIPSCs frequency was completely blocked by pretreatment with $10^{-8}$ M SP $(105.11 \pm 7.86 \%$ of control in standard external solution) without altering the mIPSC amplitude distribution (Fig. 2A,B). After washing out the SP, the facilitatory effect of ATP on glycine release gradually recovered over $30 \mathrm{~min}$. However, the inhibitory effect of SP on ATP action was blocked by adding CP 99994, a selective NK-1 antagonist (Fig. 2B). The ATP action itself was not affected by adding CP
99994. The facilitatory ratios of mIPSC frequency after external addition of ATP were $491.21 \pm 125.29$ and $550.23 \pm 115.29 \%$ $(n=4)$ (in the external solution) with or without CP 99994, respectively (Fig. 2B). There was no significant difference between the two values. These results indicate that activation of NK-1 receptor can modulate the $\mathrm{P}_{2 \mathrm{X}}$ receptors on glycinergic presynaptic nerve terminals.

As noted above, the ATP facilitation of mIPSC frequency depends on external calcium. To demonstrate that most of this effect was mediated by $\mathrm{P}_{2 \mathrm{X}}$ receptor rather than voltagedependent calcium channels, we added $0.1 \mathrm{mM} \mathrm{Cd}^{2+}$ to the external solution. Figure 3 shows that the addition of $\mathrm{Cd}^{2+}$ to control case results in a modest decrease of the mIPSC frequency (Fig. $3 B$ ). In the presence of $\mathrm{Cd}^{2+}$, ATP still had a significant facilitatory effect, although less than in the absence of the $\mathrm{Cd}^{2+}$ (Fig. $3 C$ ). These results are in substantial agreement with those found by Rhee et al. (2000) and suggest that the facilitatory effect of ATP is via activation of $\mathrm{P}_{2 \mathrm{X}}$ receptors. Terminal depolarization may secondarily activate voltage-dependent calcium chan- 
A Control

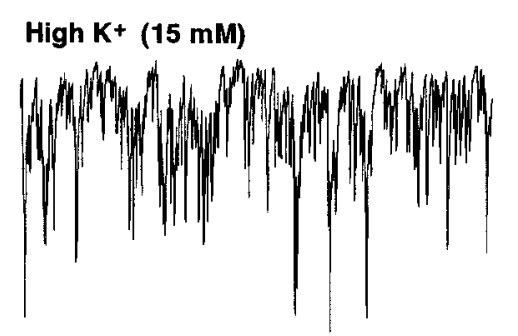

SP $10^{-7} \mathrm{M}+\mathrm{High} \mathrm{K}^{+}$

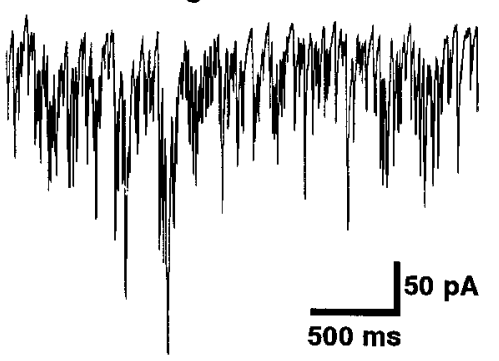

B
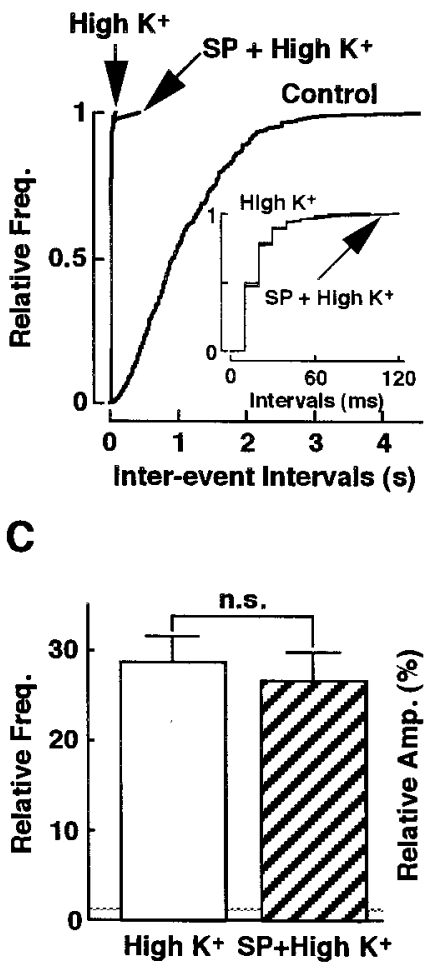
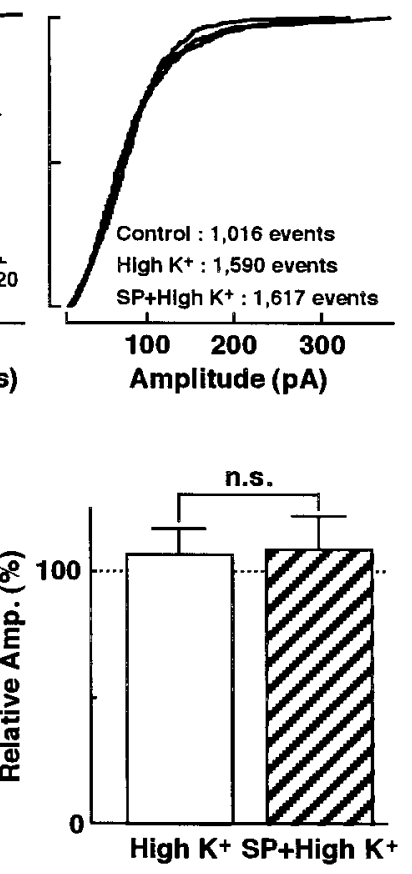

Figure 4. SP does not inhibit the facilitatory effect of elevated external potassium concentration on mIPSC frequency. $A$, mIPSC recordings for control, in elevated potassium $(15 \mathrm{~mm})$, and in elevated potassium + SP $\left(10^{-6} \mathrm{M}\right) . B$, Normalized cumulative interevent histograms show that SP does not reduce the frequency stimulation induced by the high potassium. The inset shows the same data set at an expanded time scale. The corresponding amplitude cumulative histogram also shows no differences. $C$, The bar graphs show that there are no significant differences between the high potassium with or without $10^{-6} \mathrm{M}$ SP for mIPSC frequency or amplitude $(p>0.05)$. nels, which then further contribute to the increase in mIPSC frequency.

The SP effect also does not appear to be mediated through the modulation of voltage-dependent calcium channels. As shown in Figure 4, the increase in mIPSC frequency was stimulated by depolarizing the terminal with high $(15 \mathrm{~mm}) \mathrm{K}^{+}$with no change of the relative mIPSC amplitude. Unlike the case for the ATP stimulation, SP $\left(10^{-6} \mathrm{M}\right)$ was unable to inhibit the stimulation caused by high $\mathrm{K}^{+}$(Fig. 4B,C). These results suggest that SP does not inhibit the release process or the voltage-dependent calcium channels.

To address the functional interaction between NK-1 and $\mathrm{P}_{2 \mathrm{x}}$ receptors on the glycinergic presynaptic nerve terminals, the intracellular mechanisms were investigated using pharmacological techniques. A previous report suggested that $\mathrm{P}_{2 \mathrm{X}}$ receptors could be modulated by PKA and PKC in Deiters cells (Chen and Bobbin, 1998). We therefore investigated whether the inhibitory effect of SP on ATP action is related to the PKA intracellular pathway. With or without externally applied KT5720, a PKAselective antagonist, ATP almost equally facilitated the mIPSCs frequency $(418.56 \pm 43.9$ and $502.86 \pm 54.42 \%$ of control in standard external solution, respectively; $n=4$ ) without altering the mIPSC amplitude distribution. In the presence of both KT5720 and SP, however, ATP failed to increase the mIPSC frequency (Fig. $5 A, B$ ), indicating that the effect of $\mathrm{SP}$ on $\mathrm{P}_{2 \mathrm{X}}$ receptors are not mediated through the PKA pathway in the glycinergic presynaptic nerve terminals.

Therefore, we examined the SP effect on ATP action in the presence of phorbol 12-myristate 13-acetate (PMA), a selective PKC activator. If PKC mediates the SP modulation of the ATP stimulation, then the application of PMA should inhibit the ATP response. Moreover, if PMA saturates the PKC binding sites, then additional activation through SP might be impossible. We found that regardless of the presence of PMA in the external

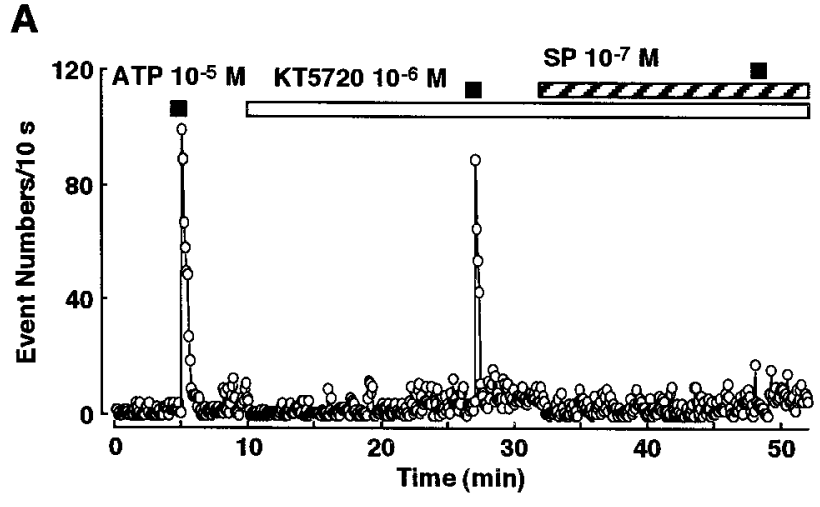

B

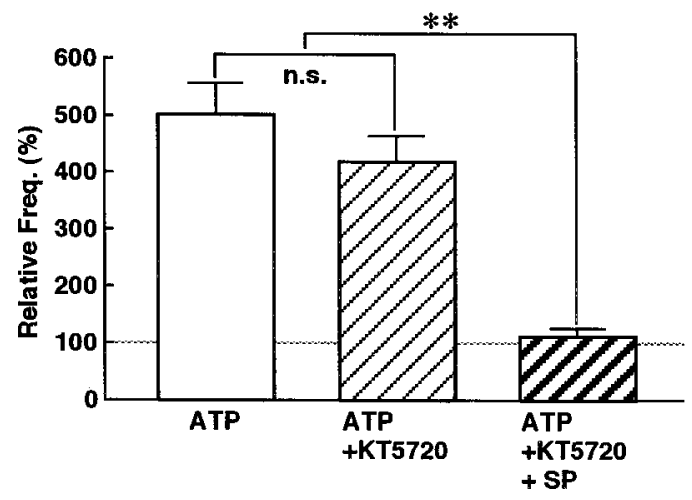

Figure 5. PKA does not affect SP action. A. Time course of event numbers per $10 \mathrm{sec}$. ATP increased the $\mathrm{mIPSC}$ frequency in the presence of $10^{-6}$ M KT5720, a PKA-selective antagonist. The ATP action was still completely blocked by adding $10^{-7}$ M SP. B, Histogram of the mIPSC frequency during the application of ATP with or without KT5720 and in the presence of both ATP and KT5720 with SP. Asterisks represent statistically significant differences $(* * p<0.01 ; n=4)$. 


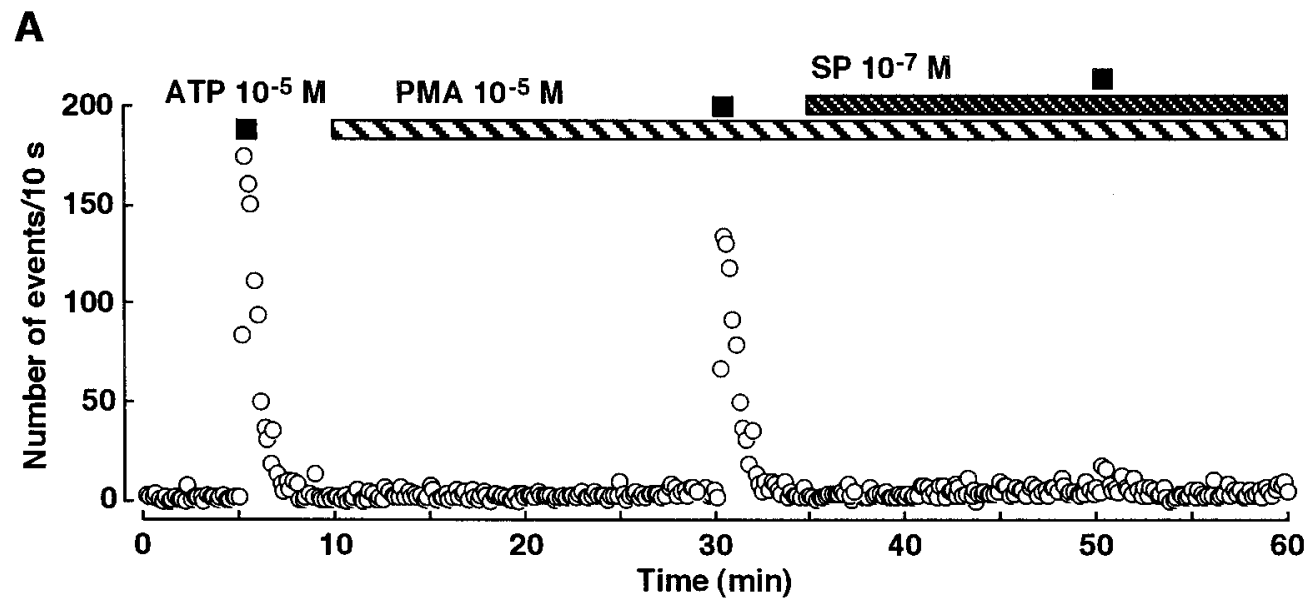

PKC does not affect SP action. $A$, Time course of the number of events per $10 \mathrm{sec}$. The activation of PKC by PMA, a selective PKC activator, did not affect the facilitatory action of ATP on mIPSC frequency. Successive applications of SP completely blocked the facilitatory effect of mIPSC frequency by ATP in the presence of PMA. B, Normalized cumulative frequency distribution (left) and current amplitude distribution (right) of ATP with or without SP in the presence of PMA. $C$, Effect of ATP on mIPSC frequency in the standard external solution with or without SP in the presence of PMA. Histogram of the mIPSC frequency during the application of ATP with or without PMA and in the presence of PMA with or without SP. Asterisks represent statistically significant difference $(* * p<0.01 ; n=4)$.

B

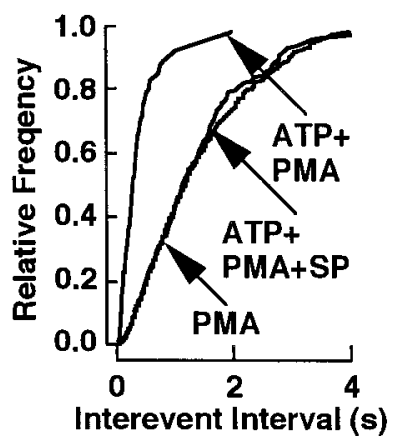

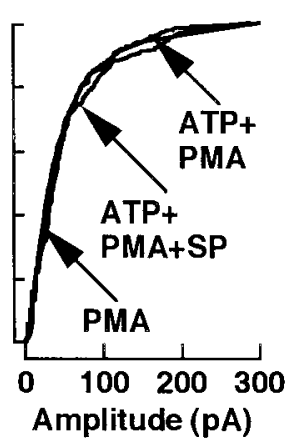

C

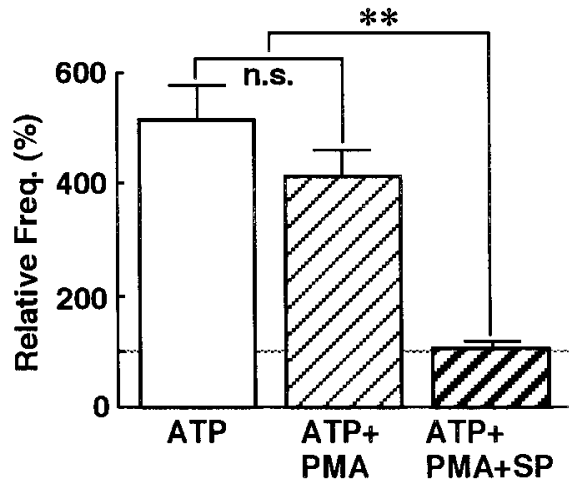

solution, ATP equally potentiated the mIPSCs frequency $(525.87 \pm 59.617$ and $413.82 \pm 46.23 \%$ of control in standard external solution, respectively; $n=4$ ) without altering the mIPSC amplitude distribution (Fig. 6). The facilitatory action of ATP on mIPSC frequency disappeared in the presence of both SP and PMA without changing the mIPSC amplitude, indicating that PKC does not mediate the inhibitory effect of SP on ATP action.

The increase of mIPSC frequency by $\mathrm{P}_{2 \mathrm{X}}$ receptor activation is induced by $\mathrm{Ca}^{2+}$ entry into the terminal (Rhee et al., 2000). We, therefore, wished to investigate the possible role of the calciumcalmodulin system (Ca-CAM system) in the mediation of the SP response. Figure 7 shows that ATP stimulation of mIPSC frequency was unaffected by W-7, a Ca-CAM antagonist, and persisted in the presence of SP with W-7 (Fig. 7A). ATP potentiated the mIPSCs frequency in the external solution with or without SP in the presence of $10^{-7} \mathrm{M} \mathrm{W}-7$ (677.85 $\pm 104.67 \%$ with ATP, $449.28 \pm 35.55 \%$ with ATP $+\mathrm{W}-7$, and $446.69 \pm 46.34 \%$ ATP + $\mathrm{W}-7+\mathrm{SP}$ of control in external solution; $n=4$ ) without altering the mIPSC amplitude (Fig. 7C). We therefore investigated whether the calmodulin-activated kinase, $\mathrm{Ca}^{2+} /$ calmodulindependent protein kinase II (CaMKII), mediated the SP action. In the presence of KN-62, a CaMKII antagonist, SP once again failed to block the facilitatory effect of ATP as shown in Figure 8. In standard W-7 and W-7 + SP external solutions, ATP potentiated the mIPSCs frequency $(457.8 \pm 41.42 \%$ in standard external solution, $429.59 \pm 30.03$ and $341.51 \pm 22.97 \%$ in external solution with $\mathrm{W}-7$ and $\mathrm{W}-7+\mathrm{SP}$, respectively; $n=4$ ) without altering the mIPSC amplitude distribution. These results suggest that SP modulates $\mathrm{P}_{2 \mathrm{X}}$ receptors through the $\mathrm{Ca}-\mathrm{CAM}$ and CaMKII pathways in the glycinergic presynaptic nerve terminals or retro- gradely by activation of postsynaptic receptors that activate some subsequent signal that affects the nerve terminals.

The action of SP could be either on presynaptic NK-1 receptors, which directly modulate presynaptic $\mathrm{P}_{2 \mathrm{X}}$ receptors, or postsynaptic NK-1 receptors, which activate pathways that produce a retrograde message that modulates the presynaptic $\mathrm{P}_{2 \mathrm{X}}$ receptors. In the hippocampus, nitric oxide produced in the postsynaptic element modulates transmitter release from the presynaptic element (Arancio et al., 1996). To eliminate the possibility of a postsynaptically mediated retrograde mechanism, we voltage-clamped the SG neurons in the whole-cell recording mode with the pipette solution containing $10^{-7}$ M W-7. Soluble second messenger components should diffuse up into the pipette. Moreover, the W-7 should block the action of postsynaptic calmodulin. The results indicate that the relative mIPSC frequency was enhanced $\sim 10$-fold $(10.7 \pm 2.87$ times) by ATP (Fig. 9A). This enhancement was abolished in the presence of SP (1.26 \pm 0.36 -fold increase, not significantly different from the control frequency). The amplitude distribution was not significantly different from control (Fig. 9B). These results strongly argue that the SP effects are not mediated by postsynaptic SP receptors that, in turn, generate a retrograde signal. Indeed, SG neurons are thought not to have NK-1 receptors (Brown et al., 1995).

\section{DISCUSSION}

The use of the "dispersed neuron with attached synaptic bouton preparation" (Akaike et al., 1992; Rhee et al., 1999) has allowed unambiguous demonstration that SP directly modulates the stimulatory effect of ATP on the release of glycine. SP has postsynaptic as well as presynaptic actions (Shapiro and Hille, 1993), 

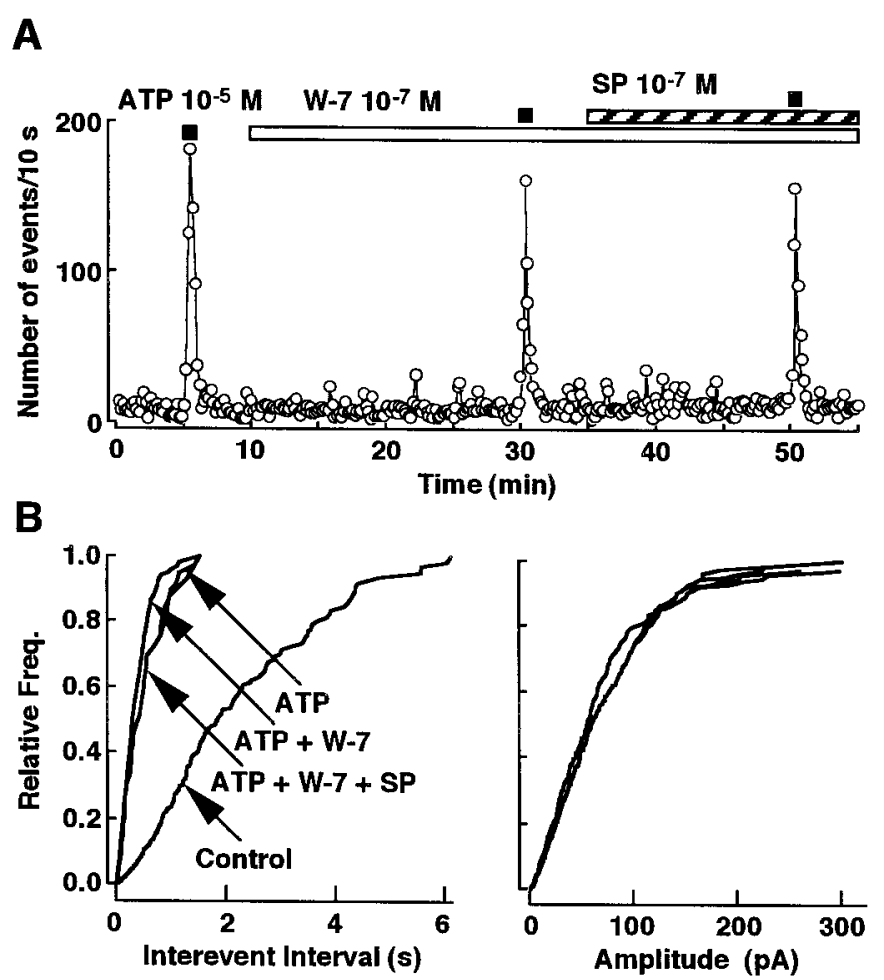

C

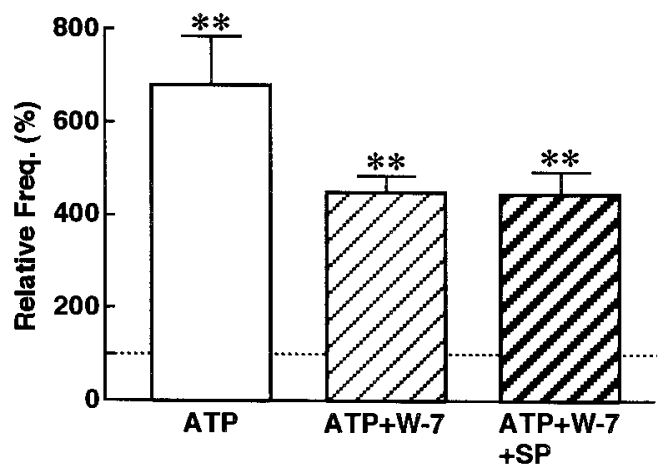

Figure 7. SP action is mediated by $\mathrm{Ca}-\mathrm{CaM} . A$, Time course of the number of events per $10 \mathrm{sec}$. SP did not block the ATP action in the presence of $\mathrm{W}-7$, a selective Ca-CAM antagonist. $B$, Normalized cumulative mIPSC frequency of ATP action in the normal external solution, in the presence of W-7, and in the presence of both W-7 and SP (left), and cumulative mIPSCs amplitude curves (right). $C$, Histogram of the mIPSCs frequency during the application of ATP with or without W-7 and in the presence of W-7 with or without SP.

although apparently not in SG neurons (Brown et al., 1995). In an intact spinal cord, many interneurons could participate in mediating the final effect on glycine release. In the synaptic bouton, the entire interneuron circuitry has been removed so that only the presynaptic terminals remain. Under such simplified conditions, we were able to demonstrate a novel mechanism of the modulation of the stimulatory action of ATP. This is, as far as we have been able to determine, the first demonstration of the presynaptic modulation of one presynaptic receptor by another. Thus, this particular action of SP requires the concomitant activation of presynaptic $\mathrm{P}_{2 \mathrm{X}}$ receptors. The inhibitory action of SP in the presence of ATP acts like a logical conditional-negation operation: SP alone does nothing, ATP alone stimulates, and the combination inhibits the ATP stimulation.
$\mathbf{A}$

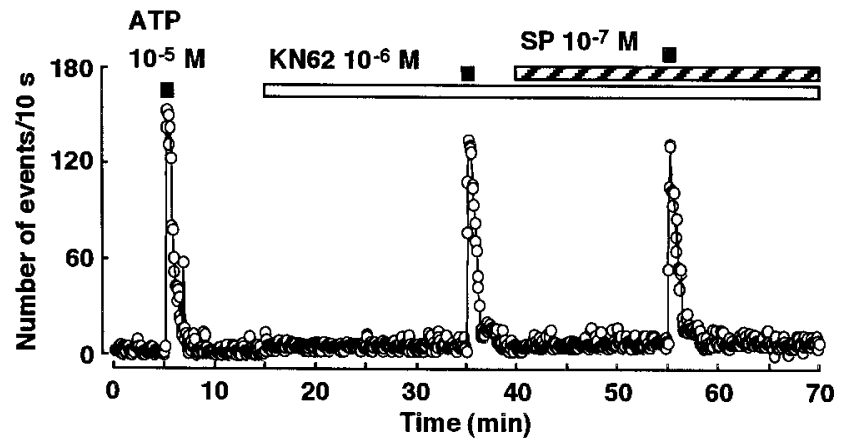

B

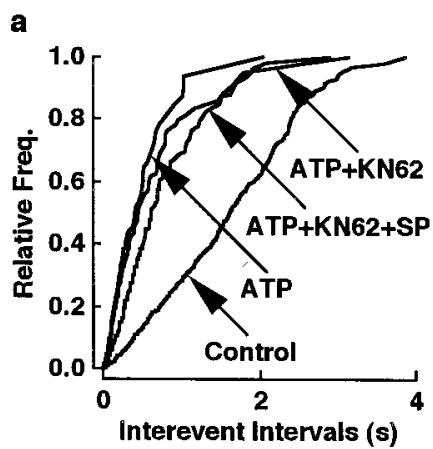

b

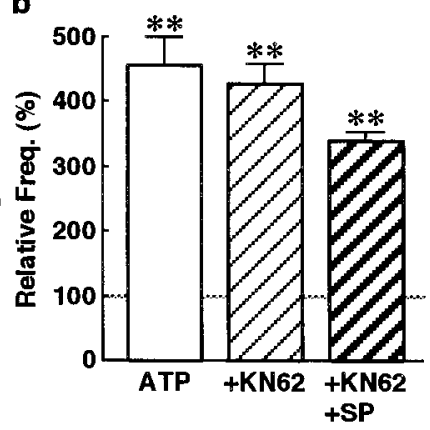

Figure 8. CaMKII participates in SP action. A, Time course of number of events per $10 \mathrm{sec}$ is plotted. SP did not block the ATP action in the presence of $\mathrm{KN}-62$, a selective CAMII antagonist. $B a$, Normalized cumulative mIPSC frequency of ATP action in the normal external solution, in the presence of $\mathrm{KN}-62$, and in the presence of both KN-62 and SP (left). Bb, Effects of ATP action on mIPSC frequency in the standard external solution and with or without SP in the presence of KN-62.
A

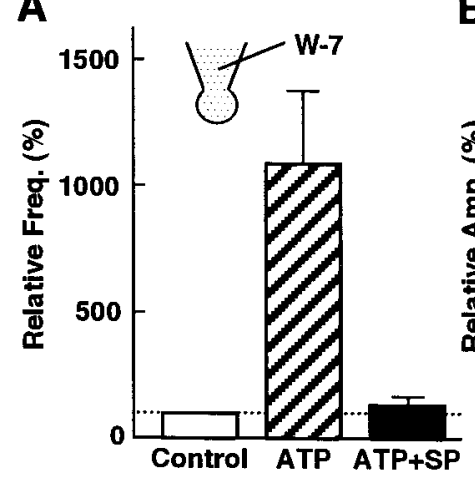

B

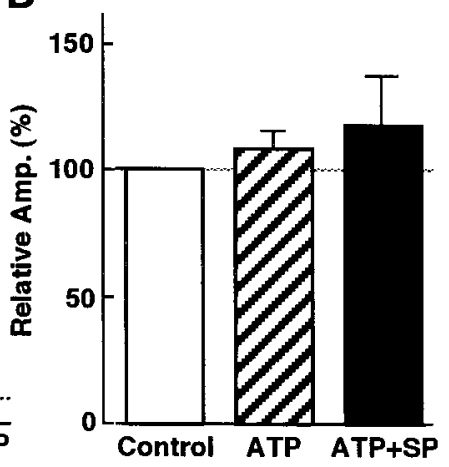

Figure 9. SP action is not mediated by a retrograde messenger from the postsynaptic element. $A$, Histogram of the mIPSC frequency in SG cells perfused with a pipette solution containing $10^{-7} \mathrm{M} \mathrm{W}-7$ in the whole-cell recording mode. The graphs show the control, the effect of ATP stimulation, and the inhibition of the ATP stimulation by SP. B. Histograms showing a lack of effect on mIPSC magnitude of W-7 dialyzed in the postsynaptic cell body.

Using pharmacological agents, we have been able to demonstrate that the SP modulation of $\mathrm{P}_{2 \mathrm{X}}$ receptors involves the CAM kinase II pathway. Inhibition of either calmodulin by W-7 or of the CaMKII by KN-62 suppressed the inhibitory action of SP on the ATP stimulation of mIPSC frequency. Because the $\mathrm{P}_{2 \mathrm{X}}$ receptor acts to promote $\mathrm{Ca}^{2+}$ permeability, the activation of the calmodulin pathway by SP may be enhanced by preactivation of 
the $\mathrm{P}_{2 \mathrm{X}}$ pathway. Our data do not rule out the possibility of another intervening step between the kinase activity and the final reduction of the ATP effect. Our data also does not unambiguously demonstrate that the $\mathrm{P}_{2 \mathrm{X}}$ receptor has been modulated. SP could, for example, block some distal step in the release process and leave the $\mathrm{P}_{2 \mathrm{X}}$ receptor unaffected. Indeed a role for CAM kinase in the process of vesicle docking has been proposed (Llinas et al., 1991). The observation that SP has little effect on spontaneous release does argue against a direct effect of SP on the release process itself. Moreover, SP had no effect on the increase in mIPSC frequency induced by elevated external potassium that presumably depolarized the terminal. This result argues against an inhibitory effect of SP on either the release process or the voltage-dependent calcium channels. It may be, however, that there are, in fact, partial inhibitory reactions that are overwhelmed and saturated by the high $(15 \mathrm{~mm}) \mathrm{K}^{+}$used in this experiment. Furthermore, because the ATP stimulation itself was only slightly effected by $\mathrm{Cd}^{2+}$, the ATP-induced response was probably not mediated through voltage-dependent calcium channels (Rhee et al., 2000). Hence, a modulatory effect of SP on ATP-stimulated calcium channels is unlikely. A direct effect of the CaMKII on the $\mathrm{P}_{2 \mathrm{X}}$ receptor activation could be determined by imaging calcium entry into the terminal in the presence and absence of SP.

It may seem surprising that SP activates the calmodulinCaMKII pathway at all. Calmodulin is activated by calcium ions that presumably increase in intracellular concentration after $\mathrm{P}_{2 \mathrm{X}}$ activation. SP could perhaps release local calcium stores to further activate the calmodulin. Indeed, SP applied locally to cultured dorsal root neurons caused the intracellular calcium levels to rise briefly. The response appeared to desensitize after repeated applications (Marvizon et al., 1998). Similarly Li and Zhao (1998) have shown that small rat dorsal root ganglion cells express NK-1 receptors that produce long-lasting inward currents presumably through a nonselective, calcium-permeable cation channel. They also suggest that autoreceptors on the primary afferent terminals could be responsible for hyperalgesia. Another interesting possibility is that the calmodulin is activated by $\mathrm{P}_{2 \mathrm{X}}$ receptor activation but cannot activate CaMKII that is in an inactive form. SP, in this model, would then function to activate the CaMKII (by some unknown pathway), which could then be activated by $\mathrm{Ca}$-calmodulin triggered by the calcium influx through the $\mathrm{P}_{2 \mathrm{X}}$ receptor. Thus, not only would the SP inactivate the ATP response, but the SP effect would require an elevated intracellular calcium concentration from either the $\mathrm{P}_{2 \mathrm{X}}$ receptor or some other source. This suggestion that the CAM kinase requires activation by SP implies that merely raising intracellular $\mathrm{Ca}^{2+}$ by through the voltage- or ligand-dependent channels would be incapable of activating the kinase.

The role of CAM kinase II in the mediation of the ATP receptor modulation is reminiscent of the mechanisms underlying LTP. Activation of postsynaptic receptors on the SG cells could activate the CAM kinase pathway (via $\mathrm{Ca}^{2+}$ and calmodulin), in turn activating nitric oxide synthase. The nitric oxide could then diffuse retrogradely back to the presynaptic terminals and alter release (Arancio et al., 1996). Our experiments in which the SG cells were patch-clamped in whole-cell mode with W-7 included in the pipette strongly argue against such a model. Mobile components such as calmodulin, CAM kinase, ATP, L-arginine should all diffuse up the tip of the pipette. Moreover, W-7 should block any residual calmodulin effect.

The synaptic bouton preparation cannot, of course, demon- strate how SP functions physiologically. Behavioral and psychophysical experiments are necessary to discriminate reflexive, sensory, and affective dimensions. Indeed, the role of SP appears to reside partly in its site of action. Lamina I neurons bearing NK-1 receptors appear to be involved in intensity coding of pain, whereas the deep neurokinin-1 cells seem to be involved in spatial localization or submodality discrimination (Polgar et al., 1999). Our results are consistent with the suggestion that in severe pain the SP modulation of the $\mathrm{P}_{2 \mathrm{X}}$ receptor results in a decreased inhibitory input to the SG cells. The exact consequences of such modulation of SG excitability depend, of course, on whether the SG neurons are themselves excitatory or inhibitory with respect to the pain pathway. In view of the autophosphorylating property of CAM kinase II, the modulating effect of SP could be greatly prolonged and constitute a mechanism for promoting allodynia and hyperalgesia. Future experiments will be required to determine the time course of the modulatory effects of SP and the role of specific phosphatases.

\section{REFERENCES}

Akaike N, Harata N (1994) Nystatin perforated patch recording and its application to analysis of intracellular mechanisms. Jpn J Physiol (Lond) 44:433-473.

Akaike N, Harata N, Ueno S, Tateishi N (1992) GABAergic synaptic current in dissociated nucleus basalis of Meynert neurons of the rat. Brain Res 570:102-108.

Ankri N, Legendre P, Faber DS, Korn H (1994) Automatic detection of spontaneous synaptic responses in central neurons. J Neurosci Methods $52: 87-100$.

Arancio O, Kiebler M, Lee CJ, Lev-Ram V, Tsien RY, Kandel ER, Hawkins RD (1996) Nitric oxide acts directly in the presynaptic neuron to produce long-term potentiation in cultured hippocampal neurons. Cell 87:1025-1035.

Brown JL, Liu H, Maggio JE, Vigna SR, Mantyh PW, Basbaum AI (1995) Morphological characterization of substance $P$ receptorimmunoreactive neurons in the rat spinal cord and trigeminal nucleus caudalis. J Comp Neurol 356:327-344.

Chapman V, Dickenson AH (1993) The effect of intrathecal administration of RP67580, a potent neurokinin 1 antagonist on nociceptive transmission in the rat spinal cord. Neurosci Lett 157:149-152.

Chen C, Bobbin RP (1998) $\mathrm{P}_{2} \mathrm{X}$ receptors in cochlear Deiters' cells. Br J Pharmacol 124:337-344.

Li HS, Zhao ZQ (1998) Small sensory neurons in the rat dorsal root ganglia express functional NK-1 tachykinin receptor. Eur J Neurosci 10:1292-1299.

Llinas R, Gruner JA, Sugimori M, McGuinness TL, Greengard P (1991) Regulation by synapsin I and $\mathrm{Ca}^{2+}$-calmodulin-dependent protein kinase II of the transmitter release in squid giant synapse. J Physiol (Lond) 436:257-282.

Lundquist CT, Nassel DR (1997) Peptidergic activation of locust dorsal unpaired median neurons: depolarization induced by locustatachykinins may be mediated by cyclic AMP. J Neurobiol 33:297-315.

Luo W, Sharif TR, Houghton PJ, Sharif M (1997) CGP 41251 and tamoxifen selectively inhibit mitogen-activated protein kinase activation and c-Fos phosphoprotein induction by substance $\mathrm{P}$ in human astrocytoma cells. Cell Growth Diff 8:1225-1240.

Mantyh PW, Rogers SD, Honore P, Allen BJ, Ghilardi JR, Li J, Daughters RS, Lappi DA, Wiley RG, Simone DA (1997) Inhibition of hyperalgesia by ablation of lamina I spinal neurons expressing the substance P receptor. Science 278:275-279.

Margeta-Mitrovic M, Grigg JJ, Koyano K, Nakajima Y, Nakajima S (1997) Neurotensin and substance P inhibit low- and high-voltage activated $\mathrm{Ca}^{2+}$ channels in cultured newborn rat nucleus basalis neurons. J Neurophysiol 78:1341-1352.

Martin TV, Wheeler MA, Weiss RM (1997) Neurokinin induced inositol phosphate production in guinea pig bladder. J Urol 157:1098-1102.

Marvizon JC, Eskandari S, Ennes HS, Mayer EA (1998) Substance P induces brief, localized increase in $\left[\mathrm{Ca}^{2+}\right]_{\mathrm{i}}$ in dorsal horn neurons. NeuroReport 9:3369-3374.

Nishimura K, Frederick J, Kwatra MM (1998) Human substance P receptor expressed in Sf9 cells couples with multiple endogenous G-proteins. J Recept Signal Transduct Res 18:51-65.

Polgar E, Szucs P, Urban L, Matesz K, Nagy I (1999) Immunohistochemical localization of neurokinin-1 receptor in the lumbar spinal 
cord of young rats: morphology and distribution. Somatosens Mot Res 16:361-368.

Rhee JS, Ishibashi H, Akaike N (1999) Calcium Channels in the GABAergic presynaptic nerve terminals projecting to Meynert neurons of the rat. J Neurochem 72:800-807.

Rhee JS, Wang ZM, Nabekura J, Inoue K, Akaike N (2000) ATP facilitates spontaneous glycinergic IPSC frequency at dissociated rat dorsal horn interneuron synapses. J Physiol (Lond) 524:471-483.

Runer T, Lindberg S (1999) Ciliostimulatory effects mediated by nitric oxide. Acta Otolaryngol 119:821-825.

Seguin L, Le Marouille-Girardon S, Millan MJ (1995) Antinociceptive profiles of non-peptidergic neurokinin 1 and neurokinin 2 receptor antagonists: a comparison to other classes of antinociceptive agent. Pain 61:325-343.

Shapiro MS, Hille B (1993) Substance P and somatostatin inhibit calcium channels in rat sympathetic neurons via different $G$ protein pathways. Neuron 10:11-20.

Yamada T, Endoh T, Suzuki T (1999) Inhibition of calcium channels by neurokinin receptor and signal transduction in hamster submandibular ganglion cells. J Auton Nerv Syst 76:1-8.

Young KW, Pinnock RD, Gibson WJ, Young JM (1998) Dual effects of histamine and substance $\mathrm{P}$ on intracellular calcium levels in human U373MG astrocytoma cells: role of protein kinase C. Br J Pharmacology 123:545-557. 